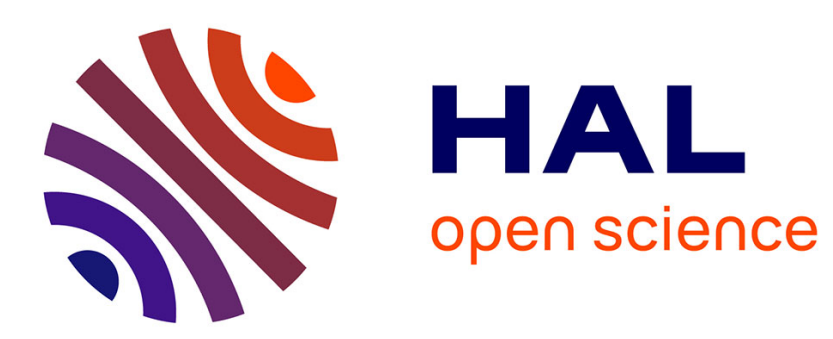

\title{
Detonation Generation and Propagation in Homogeneous Liquid Explosives
}

\author{
H. Presles, P. Vidal
}

\section{To cite this version:}

H. Presles, P. Vidal. Detonation Generation and Propagation in Homogeneous Liquid Explosives. Journal de Physique IV Proceedings, 1995, 05 (C4), pp.C4-143-C4-152. 10.1051/jp4:1995412 . jpa00253711

\section{HAL Id: jpa-00253711 https://hal.science/jpa-00253711}

Submitted on 1 Jan 1995

HAL is a multi-disciplinary open access archive for the deposit and dissemination of scientific research documents, whether they are published or not. The documents may come from teaching and research institutions in France or abroad, or from public or private research centers.
L'archive ouverte pluridisciplinaire HAL, est destinée au dépôt et à la diffusion de documents scientifiques de niveau recherche, publiés ou non, émanant des établissements d'enseignement et de recherche français ou étrangers, des laboratoires publics ou privés. 


\section{Detonation Generation and Propagation in Homogeneous Liquid Explosives}

H.N. Presles and P. Vidal

Laboratoire de Combustion et de Détonique, UPR 9028 du CNRS, ENSMA, BP. 109, 86960 Futuroscope cedex, France

\section{Foreword}

The goal of this paper is to present the main features of detonation generation and propagation in liquid explosives. Most of the results are related to Nitromethane (NM) since it is the most studied liquid explosive.

\section{I - Introduction}

Depending on whether they are homogeneous or heterogeneous, explosive media have specific detonic properties which are related to different heat release mechanisms. Before describing the ignition, propagation and extinction of a detonation in a liquid explosive charge, it is useful to recall some specific features of liquid explosives.

The latter are homogeneous in normal conditions but by adding heterogeneities, such as solid particles or bubbles, they can exhibit solid explosives properties.

Homogeneous liquid explosives are transparent to the visible light so that the radiations emitted by the detonation products can be recorded while the detonation wave propagates inside the explosive charge.

Liquid explosive densities are of order $1 \mathrm{~g} / \mathrm{cm}^{3}$ so that the detonation pressure is in the range 10 to $20 \mathrm{GPa}$. With such a pressure level the compressibily of the confinement has a great influence on the shape of the detonation front and on the critical diameter.

When liquid explosives are submitted to a shock or a detonation wave they exhibit a phenomenon called "electrical polarization effect". For instance, this effect is very useful to look at the consecutive events leading to the ignition of a detonation.

If cavitation is generated in the liquid explosive charge under precursor effects propagating through the confinement, an other detonation propagation regime called "low velocity detonation" can be obtained. For safety reasons, it is very important to understand this particular regime.

\section{II - Detonation ignition in liquid explosives submitted to a plane shock wave}

The processes involved in the detonation ignition in liquid explosives submitted to a plane shock wave have been clearly established in 1961 by Campbell et al. /1/ after the 
preliminary work of Chaiken /2/. Using an other experimental technique, Hardesty in 1976/3/ confirmed all these processes. When a liquid explosive is submitted to a plane shock wave of proper characteristics, a thermal explosion occurs after an induction time $\tau$ (Fig. 1), leading to a detonation wave which propagates into the compressed explosive at a velocity $D^{*}$ higher than the shock wave velocity U. When this detonation wave overcomes the shock wave it becomes an overdriven detonation propagating in the explosive at rest, its velocity decreasing toward the normal detonation velocity $\mathrm{D}$.

Assuming that the chemical reaction follows an Arrhenius rate law, the induction time can be approximated by the relation

$$
\tau=\mathrm{KT}^{2} \mathrm{c} \exp \left(\frac{\mathrm{E}}{\mathrm{RT}_{\mathrm{c}}}\right)
$$

$T_{c}$ is the shock temperature of the explosive and $E$ the activation energy.

In agreement with this relation, experimental results show a great dependance of the induction delay on the initial temperature $T_{0}$ of the liquid explosives $\left(T_{c}\right.$ depends on $\left.T_{0}\right)$.

Measuring $\tau$ for different shock strenghts and calculating the corresponding liquid temperature $T_{c}$, it has been shown /4/ that the activation energy of NM compressed by a shock wave is about $25 \mathrm{kcal} / \mathrm{mole}$, that is half of the value for the gas-phase unimolecular decomposition.

In most of the studies the diagnostic information during the subsequent events of initiation was obtained from a streak camera looking towards the compressed explosive through the shock wave. In some explosives, like NM, light from the detonation propagating in the compressed explosive is weak but readily photographed. With some other explosives, there is a lack of luminosity. In 1965 TRAVIS /5/ has shown that electrical signals are generated by initiation processes occuring in dielectric liquid explosives filling a plane capacitor. A few years before, EICHELBERGER and HAUVER /6/ and HARRIS /7/ have reported studies on the charge generation by shock in inert dielectric. They have considered the effect to be due to mechanical polarization of the molecules produced at the shock front.

As the initial shock wave enters the liquid explosive and propagates, it polarizes the molecules in a thin layer (Fig. 2). Then the polarization relaxes rapidly. Using the ALLISON theory $/ 8 /$ to analyse the electrical response of NM compressed by shock waves in the range 3 to $8 \mathrm{GPa}$, we have shown that the polarization relaxation time is of the order of $10 \mathrm{~ns} / 9 /$.

When detonation starts at the interface between the barrier and the explosive at time $\tau$, it polarizes a second layer of molecules which leads to a positive signal and when it catches the leading shock wave only one polarized layer remains. A negative signal corresponds to this event. As the detonation wave gets closer to the second metallic plate the electrical pulse rises rapidly because of the rapidly decreasing effective electrode spacing. TRAVIS has shown that the times of occurence of the initiation events measured by both the polarization and optical techniques are the same. This electrical technique is very useful to measure very short induction time. 
Mechanical orientation of the dipoles submitted to shock wave is a possible cause of the electrical phenomena associated with shock or detonation propagation, but it has not been proved and some more fundamental researches should be started to really understand it.

\section{III - Detonation propagation}

Many experiments have shown that the relationship between explosive charge size and steady state detonation velocity is qualitatively different for homogeneous and heterogeneous explosives.

For both kind of explosives, the detonation pressure is so high that part of the chemical energy is used to produce lateral material motion. As a consequence, the detonation front is curved and its velocity decreases with the charge diameter down to a minimum value called the failure or the critical diameter, below which no steady wave can propagate. The corresponding charge diameter is termed critical diameter.

The detonation velocity of liquid explosives decreases linearly with respect to the reciprocal of the charge diameter (Fig. 3) and is nearly independant of the confinement nature. The detonation velocity decrement between infinite and critical diameter is very small (about $1 \%$ ). The corresponding curve for heterogeneous explosives shows a strong downward concavity, a larger velocity decrement and a strong sensitivity to the confinement nature.

This is the case with heterogeneous mixtures based on NM and containing beads $/ 10 /$ or glass micro-balloons (GMB) (Fig. 3) /11/.

Following CAMPBELL and ENGELKE /12/, the differences between the curves for homogeneous liquid and heterogeneous explosives is due to different mechanisms supporting wave propagation.

Homogeneous burn is the mechanism involved in the detonation of homogeneous explosives while in the case of heterogeneous explosives it is re-inforced by "hot spots". The lack of concave part in the homogeneous explosives curve should be due to th iack of the hot spot mechanism.

The influence of chemical sensitization of NM on its steady detonation propagation has also been studied by ENGELKE /13/. He has shown that very small amount of amines (DETA) produces a significant reduction of the NM critical diameter. For instance, adding 0.03 weight per cent of DETA to NM reduces the critical diameter by an amount of $40 \%$. A so small amount of chemical impurity has no influence on the initial density nor on the specific heat of reaction of pure NM so that only the chemical kinetics is altered. From detonation velocity measurements of mixtures containing 0.03 weight per cent of DETA, ENGELKE deduced that the onedimensional reaction zone length of the detonation in this mixture is $80 \%$ of that in pure NM.

The shape of the detonation front can also be used for obtaining information about the chemical kinetics because it is determined by the interaction between fluid mechanics and the heat release rate inside the reaction zone 
BDZIL et al $/ 14 /$, using experimental measurements of detonation wave shape and velocity in combination with a quasi-one dimensional theory of the processes inside the reaction zone, have evaluated the parameters of the Arrhenius law for NM. They got a rather high value of the activation energy $(92 \pm 23 \mathrm{kcal} / \mathrm{mole})$ in comparison with that obtained from initiation experiments.

About the detonation velocity of NM-DETA mixtures, WALKER /15/ found, with onedimensional experiments, an increase with DETA up to 0.1 weight per cent. Measuring the detonation velocity and temperature of theses mixtures confined in brass tubes, we observed that these characteristics are continuously decreasing while the DETA concentration is increasing. So these results obtained with two-dimensional axisymetric detonation do not confirm those of WALKER.

\section{IV -Three-dimensional detonation front structure}

The detonation front in some liquid explosives such as NM is not smooth /15/ and streak camera records of the emitted light shows a nonuniform burning of the explosive throughout the cross section. One can deduce that detonation in NM is unstable. To discern the details of the detonation structure it is usual to decrease the specific energy of the explosive by diluting it with some non-explosive molecule. For instance NM is usually diluted with acetone $/ 17 / / 18 / / 19 /$. Using such a mixture, we can observe that the detonation wave structure behaves similarly as in gaseous explosive with respect to dilution with an inert additive, to chemical sensitization and to detonation overdriven degree.

For example as shown on fig. 4 adding a small amount of DETA to a NM-acetone mixture reduces greatly the size of the detonation front structure $/ 20 /$. Thus, as in gaseous explosives, the three-dimensional structure is very sensititive to the chemical kinetics.

From these observations, chemical decomposition processes in homogeneous liquid and gaseous explosives look similar.

\section{V - Detonation failure and critical diameter}

Looking with framing or streak camera at the detonation front propagating in liquid explosive charge with size near the critical one, one can observe non luminous areas spreading inward from the confining wall $/ 21 /$.

Because these areas look like reaction quenching waves they are called failure waves /22/. They appear to be characteristic of homogeneous explosives. When the flow expansion is too large compared to the rate of chemical energy release, a reaction failure wave travels along the detonation front. Quasi-steady, quasi-one dimensional theoretical modellings /26/ associate a critical shock curvature and a critical velocity to this event.

Behind failure waves, there is compressed explosive which can thermally explode and initiate again a detonation. 
As the detonation process in charge size near the critical one is unsteady and the starting of failure wave random, the best way to look at the failure mechanism is to submit a steady detonation to a sudden confinement enlargement /17/ (Fig. 5).

When the detonation passes over the corner of the confinement a failure wave takes place at the periphery and propagates symmetrically toward the axis of the charge at a constant velocity.

According to the criterion of DREMIN and TROFIMOV /23/ the critical diameter of the unconfined charge is defined by the tube diameter $\phi$ for which the re-initiated detonation in the compressed explosive overtakes the failure wave exactly on the axis.

Experiments show that the critical diameter of liquid explosives is very sensitive to the confinement nature (and also to the confinement thickness when this thickness is sufficiently small $/ 27 /$ ) and to the initial temperature. For instance, the critical diameter of NM confined in a steel tube is around $2 \mathrm{~mm}$ and $14 \mathrm{~mm}$ in glass. It decreases as the initial temperature increases with a rate of about $0,43 \mathrm{~mm} / \mathrm{C} / 24 /$.

Using the model of DREMIN and TROFIMOV, ENIG and PETRONE /25/ have shown that this can be explained by the fact the chemical kinetics is of an Arrhenius form.

\section{VI - Conclusion}

Due to different heat release mechanisms, liquid homogeneous explosives present some specific detonic properties in comparison with heterogeneous liquid or solid ones.

As there is no possibility to look straight to the chemical kinetics inside the detonation wave of condensed explosives, researches have to be undertaken to solve this problem.

One possible way is through inverse methods based for instance on realistic twodimensional detonation modelling combined with detonation wave shape measurements.

But as instabilities have been observed in the detonation of some liquid explosives, the next step would be to use a three-dimensional approach in order to understand the real detonation and to determine for instance if there is some similarity between detonation waves in gaseous mixtures and in homogeneous liquid explosives.

\section{VII - References}

11/ CAMPBELL A.W., DAVIS W.C., TRAVIS J.R., Shock initiation of detonation in liquid explosives, $3^{\text {rd }}$ Symp. on Detonation, ACR 52, 469-498, 1960.

12/ CHAIKEN R.F., Kinetics theory of detonation of high explosives, Master's thesis, Polytechnic Institute of Brooklyn, 1958. 
13/ HARDESTY D.R., An investigation of the shock initiation of liquid NM, Comb. and Flame, 27, 229-251, 1976.

14/ CHAIKEN R.F., Correlation of shock pressure, shock temperature and detonation induction time in NM, Symp. HDP, 41-53, 1978.

15/ TRAVIS J.R., Electrical transducer studies of initiation of liquid explosives, $4^{\text {th }}$ Symp. on Detonation, ACR 126, 609-615, 1965.

/6/ EICHELBERGER R.J., HAUVER G.E., Solid state transducers for recording of intense pressure pulses, Congrès sur les Ondes de détonation, CNRS Paris, 363-381, 1962.

7I HARRIS P., Mechanism for the shock polarization in dielectrics, J.Appl. Phys. 36, 739-741, 1965.

18/ ALLISON F.E., Shock induced polarization in plastics, J. Appl. Phys., 36, 7, 2111-2112, 1965.

19/ DE ICAZA-HERRERA M., PRESLES H.N., BROCHET C., Polarisation du nitrométhane sous choc, Revue de Physique Appliquée, 547-553, 1978.

/10/ ENGELKE R., Effect of the number density of heterogeneities on the critical diameter of condensed explosives, Phys. Fluids, 26, 9, 2420-2424, 1983.

/11 H.N. PRESLES, P. VIDAL, J.C. GOIS, B.A. KHASAINOV, B.S. ERMOLAEV, "Influence of glass microballons size on the detonation of NM" bases mixtures, accepted for publication in Shock Wave Journal.

/12/ CAMPBELL A.W., ENGELKE R., The diameter effect in high density heterogeneous explosives, $6^{\text {th }}$ Symp. on Detonation, ACR 221, 642-652, 1976.

113/ ENGELKE M., Effect of chemical inhomogeneity on steady-state detonation velocity, Phys. Fluids, 23, 5, 875-880, 1980.

114/ BDZIL J.B., ENGELKE R., CHRISTENSON D.A., Kinetics study of a condensed detonating explosive, J. Chem. Phys., 74, 10, 5694-5699, 1981.

115/ WALKER F.E., Initiation and detonation studies in sensitized NM, Astronautica Acta, 6, p.807 ..., 1979. 
/16/ ZELDOVICH Y.B., KORMER S.B., KRISKEVICH G.V., YUSHKO K.B., Dokl. Akad. Navk. SSSR, 171, 67, 1965.

117/ DREMIN A.N., ROZANOV O.K., TROFIMOV V.S., On the detonation of NM, Comb. and Flame, 7, 153-162, 1963.

/18/ MALLORY H.D., GREENE G.A., Lunimosity and pressure aberrations in detonating NM solutions, J. of Applied Physics, 40, 12, 4933-4938, 1969.

/19/ URTIEW P.A., KUSUBOV A.S., DUFF R.E., Cellular structure of detonation in NM, Comb. and Flame, 14, 117-122, 1970.

120/ PRESLES H.N., Nouveau critère d'étude de la sensibilisation d'explosifs liquides, CRAS, 314, II, 575-578, 1992.

121/ CAMPBELL A.W., MALIN M.E., HOLLAND T.E., Detonation in homogenous explosive, $2^{\text {nd }}$ Symp. on Detonation, 454-477, 1955.

122/ COTTER T.P., The structure of detonation in some liquid explosives, Dissertation, Cornell University, 1953.

123/ DREMIN A.N., TROFIMOV V.S., On the nature of the critical diameter, $10^{\text {th }}$ Symp. Int. on Combustion, 839-843, 1965.

124/ CAMPBELL A.W., MALIN M.E., HOLLAND T.E., Temperature effect in the liquid explosive NM, Journal of Applied Physics, 27, 6, 963, 1954.

25/ ENIG J.W., PETRONE F.J., The failure diameter theory of Dremin, $5^{\text {th }}$ Symp. Int. on Detonation, ACR 184, 99-104, 1970.

126/ STEWART D.S., BDZIL J.B., The shock dynamics of stable multi-dimensional detonation, Comb. and Flame, 72, 311-323, 1988.

/27/ FORBES J.W, LEMAR E.R., BAKER R.N., Detonation wave propagation in PBXW115, IX ${ }^{\text {th }}$ Symp. (Int.) on Detonation, OCNR 113291-7, I, 806-815, 1990. 


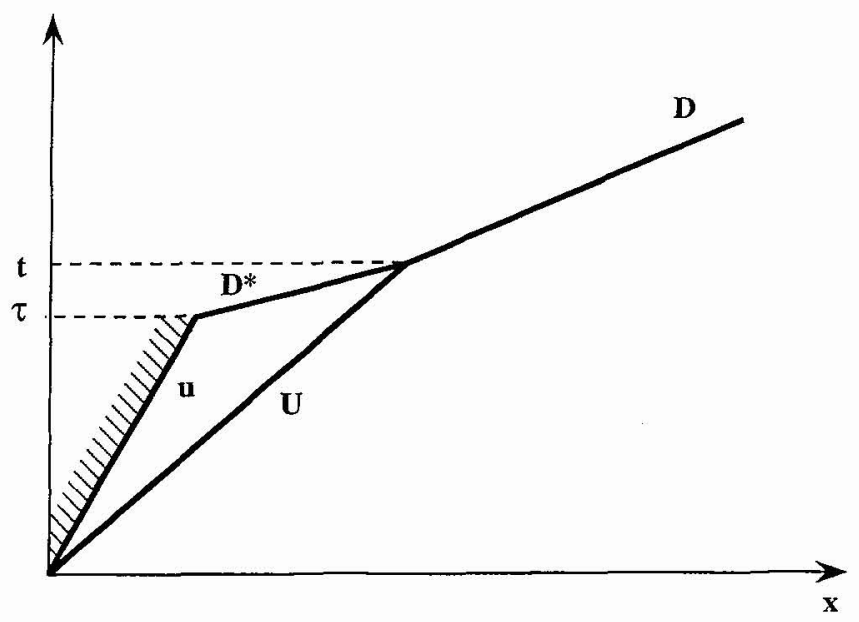

Fig. 1. Space-time representation of the events leading to the generation of a detonation in a homogeneous liquid explosive submitted to a plane shock wave

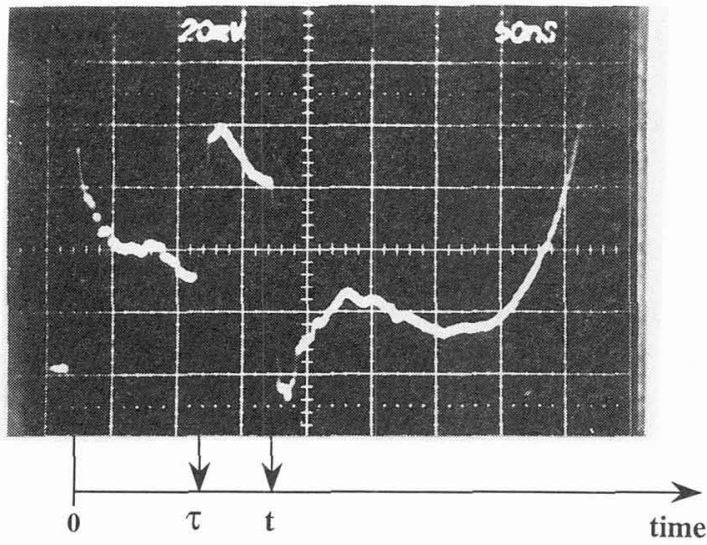

Fig. 2. Electrical signals associated with detonation generation. At $t=0$, the shock wave enters the nitromethane. $\tau$ and $t$ have the same meaning as on Fig. 1 . 


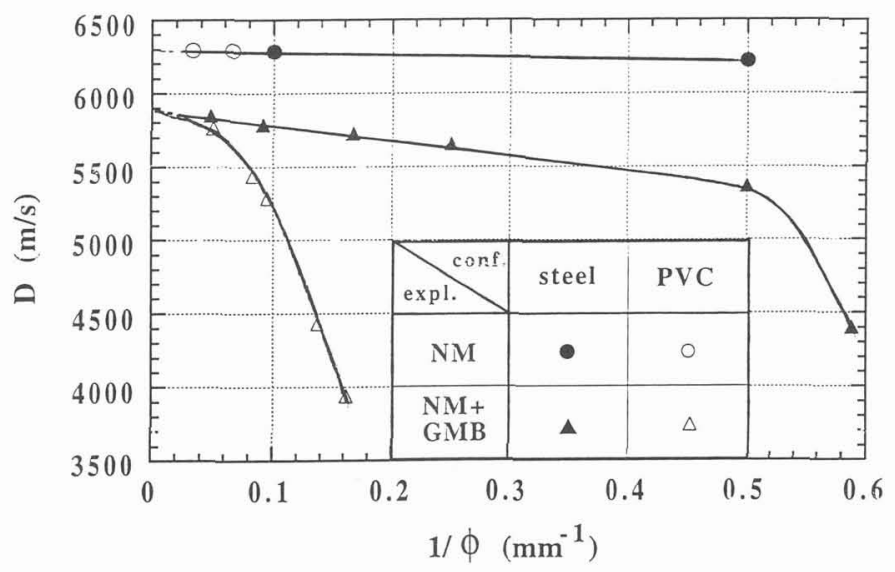

Fig. 3. Detonation velocity with respect to the reciprocal charge diameter for NM and for a heterogeneous mixture made of NM and $2 \%$ (mass fraction) of glass micro-balloons (GMB) confined in PVC and steel tubes
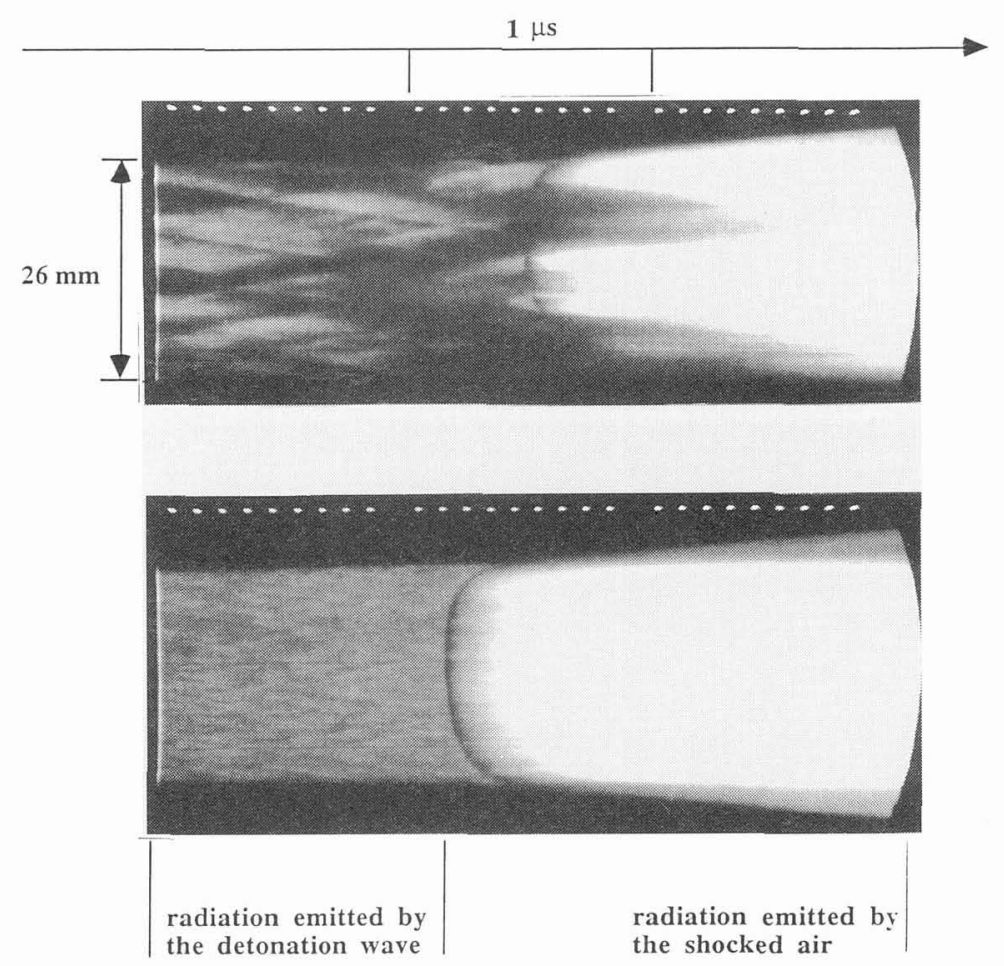

Fig. 4. Streak camera records of the radiation emitted by the detonation wave front propagating in NM-acetone mixture (upper record) and in the same mixture sensitized with DETA (lower record) 


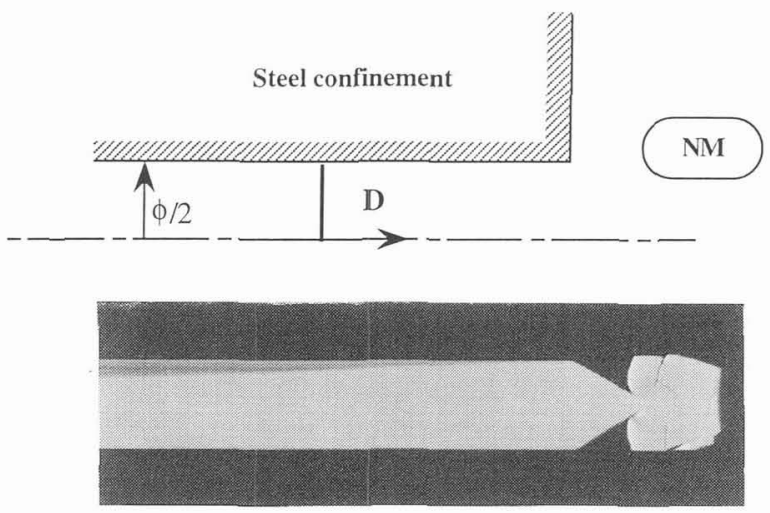

Fig. 5. Streak camera record of a detonation wave submitted to a confinement discontinuity : A conical failure wave moving with constant tranverse velocity reduces the size of the detonation front. Then re-initiation occurs. 